Ali Ardalan, Old Dominion University

Roya K. Ardalan, Old Dominion University

G. Steven Rhiel, Old Dominion University 


\begin{abstract}
Abrupt Conversion of Face-to-Face Courses to Online
Abstract

In special circumstances such as the one presented by the coronavirus universities must convert their face-to-face courses to online. This conversion is challenging for all universities, but extremely challenging for universities that offer all their courses face-to-face. This paper presents the major activities that a quick conversion from face-to-face courses to online courses should consider. This paper shows that higher education institutions can acquire the basic technology and be quickly trained to convert their face-to-face courses to online while trying to achieve the quality that is in line with the quality level defined in their organization's strategy. Keywords: Information Technology, Course delivery method, Online course delivery
\end{abstract}




\section{Abrupt Conversion of Face-to-Face Courses to Online}

\section{Introduction}

Doubtless, online education has become a method of delivering educational content by higher education institutions. Online courses and programs provide educational opportunities for students anytime, anywhere if they have access to the computing technology and the Internet. Learning communities of students and educators use state-of-the-art communication technologies to improve the delivery of educational materials and students' education and experience.

Strategic choices of higher education institutions have placed them on the online continuum. On one are those that have no online courses or programs to those on the other end that offer all the courses and programs online. Higher education institutions that are positioned in the middle of this continuum deploy both types of delivery systems and have developed both online and faceto-face student and faculty support systems to serve students and faculty. These institutions are more agile in responding to changes in demand for either type of delivery system. They have support systems and faculty who are cross-trained and can develop and offer courses and programs online and provide online support services for students and faculty.

In response to the possible consequences of contracting COVID-19, most organizations stopped normal operations. Higher education institutions were forced to convert their face-to-face courses to online during the ongoing semester. Higher education institutions that were positioned on or near the only face-to-face end of the delivery method continuum faced a more serious challenge in converting all their courses to online. The challenge was progressively less serious as the institution's position moved toward the other end of the continuum. In most cases the conversion from face-to-face to online was taking place during the semester and day-by-day and week-to-week. 
This paper discusses the requirements for development of efficient and effective online course development, delivery, and its support structure in a very short time. In addition, this paper makes recommendations on ways to support faculty in the conversion process, and ways to help students benefit from the online delivery method. These discussions are in part based on the authors' in-depth experience in developing online courses and their observations as their university converted face-to-face courses to online. The authors experienced the conversion in at least one of their courses. The reader is encouraged to consider the specific structure of the higher education institution and its online delivery and support development challenges as the requirements and recommendations are presented below. The challenge is significantly lower and more manageable for institutions that possess the expertise in and experience with online course delivery compared to institutions that have lower levels of skills and experience in this delivery method.

\section{Literature review}

The literature related to online delivery of courses and programs is extensive. A variety of issues have been dealt with in this literature. This section presents the review of literature with respect to these issues. Knowledge of this literature is helpful as face-to-face courses are converted to online and as support services take a more active role in supporting students and faculty online.

\section{Context}

Published work on comparing the two delivery methods is mixed (Hanan et al., 2015). Higher education administrators' negative perception of the effectiveness of online programs has been decreasing from 40 percent in 2003 to 23 percent in 2012 (Alsaaty et al., 2016). A Sloan 
Consortium report concluded that two-thirds of academic leaders felt that online learning is one of their critical long-term institutional strategies (Tichavsky et al., 2015).

Technologies available for online course delivery present the potential for creating completely different environments than those present in face-to-face settings (Jaiyeoba, 2019; Sozudogru et al., 2019). Skillful use of these technologies can create more effective learning opportunities than the face-to-face method. Online education has its own characteristics and its evaluation should not follow the same standards as face-to-face programs (Masoumi \& LindstrÖm, 2012). Face-to-face courses provide a natural setting for community building. Proper use of online technologies allows participants to build communities, although with a different feel and effectiveness. A shortcoming of online technologies is their inadequate support for non-verbal communication. However, these technologies prevent misconceptions that result from classmates' appearance, manners, accents, and smell. While the face-to-face method rewards students skilled in real-time thinking and communicating, online method benefits students who are skilled in thoughtful and persuasive writing (Arasaratnam-Smith \& Northcote, 2017). Also, students may select online courses because they provide them with anonymity which gives them protection against discrimination (Bawa, 2016).

Tichavsky et al. (2015) state that while students are concerned about interaction, motivation, and the comfort of familiarity, their satisfaction with both face-to-face and online courses are similar if online courses are designed based on a strong pedagogical background. Some students feel that the separation of students and instructors in online classes makes timely feedback a challenge, and negatively affects students' perception of the online learning environment. Faceto-face classes involve more communication and more rapport between the faculty and students. However, advances in technology has made interactions possible through video meeting 
software, discussion boards, wikis, email, text, and chat. In addition, students in online classes have more time to think and search before they participate in discussions and respond to questions (Ganesh et al., 2015).

\section{Student performance}

Review and analysis of pros and cons of the two delivery methods and strengths and weaknesses of different groups of participants show that the combined effect of age, gender, and ethnicity on student performance is not significant. However, students in face-to-face courses performed better than students in online courses (Hanan et al., 2015). Lee (2010) discusses the effect of culture on student's perception of quality of service of online education. He used factor analysis and concluded that American and Korean students' perception of quality of service of online education were significantly different, and that perception of quality of service is a strong predictor of online learning acceptance and satisfaction for both Korean and American students. Cultural issues are important in the development of online courses and programs as students from different regions of the world and different cultures may participate in online classes (Masoumi \& LindstrÖm, 2012).

\section{Faculty characteristics}

The faculty challenge in online education stems from the fact that developing effective methods of teaching is different from the face-to-face methods. Student satisfaction is significantly affected by the inclusion of appropriate course materials, effective use of learning techniques, integration of high-level interaction and collaboration, and providing high quality and timely student support (Arinto, 2016; Markova et al., 2017). This can be accomplished by extensive training for faculty as the results of a study that used Quality Matters standards on K12 teachers' readiness for developing and delivering online courses showed that even when 
teachers attended course development workshops, there were a significant number of teachers who were not ready to develop and/or deliver online courses (Quiroz et al., 2016). While faculty is seen as the source of information in face-to-face courses, the faculty is seen as a facilitator in online courses (Ganesh et al., 2015).

Motivational theories of self-determination in online learning indicate the importance of emphasizing students' sense of control, feelings of competency for tasks, and sense of inclusion. Self-efficacy beliefs of students and their backgrounds are directly related to their abilities to stay in the course and be successful (Bawa, 2016; Davis, 2016). Non-traditional leaners find the selfdirected learning of online courses appealing. However, they may find out that they lack the necessary skills to work with online learning technologies (Bawa, 2016). Non-traditional students may need more technical support, time, and practice to learn the learning platform well (Bawa, 2016).

Non-traditional students tend to not engage on their own, and their social needs are not usually considered in online education. This may be rectified by to incorporating activities for engaging these students and creating supportive, friendly, informal, and open environments (Davis, 2016). While it is important for faculty to know what facets of online education require additional consideration and monitoring (Harroff, 2002), faculty educating non-traditional students should be cognizant of the students' limited amount of time they have to spend on coursework. Faculty should create clear and detailed instructions, and provide frequent feedback to these students (Davis, 2016).

Gray and DiLoreto (2016) considered the effect of course structure, faculty engagement, and student engagement on student satisfaction and perceived learning. They concluded that course 
structure and faculty engagement affected student satisfaction and perceived learning significantly.

Faculty are concerned about students' technology readiness and skills, communication abilities, achievement of learning objectives, and proctoring. They are also concerned about faculty's image as online instructors, the effect on performance evaluation and tenure, technology readiness and skills, differences in workload, and engagement with students and engagement of student with student. Some faculty are reluctant to participate in online education while some others participate to learn the technology and become involved in the online environment (Wingo et al., 2017).

\section{Online program characteristics and university services}

Almost all units and offices in higher education institutions provide support for the online course delivery system (Markova, et al., 2017). A set of twenty-four benchmarks that are presented as essential components of quality online education include institutional support, course development, teaching and learning, course structure, student support, faculty support, and evaluation and assessment (Phipps \& Merisotis, 2000). Four basic principles of program planning as part of a decision-making framework that include define learning objectives, develop appropriate learning experiences, maximize learning identified experiences, and evaluate and revise learning objectives (Tyler, 1950) are used as a basis for developing many adult education program planning models. The statement issued by regional U.S. accrediting bodies on the online programs includes five components: institutional context and commitment, curriculum and instruction, faculty support, and evaluation and assessment (Benson, 2003). Determining the factors that affect the quality of online education has been the subject of extensive research efforts (Frydenberg, 2002; Benson, 2003; Harroff, 2003; McGorry, 2003; 
Zhao, 2003; Mariasingam \& Hanna, 2006; Young \& Norgard, 2006; Chua \& Lam 2007; Jung, 2011; Masoumi \& LindstrÖm, 2012; Wingo et al., 2017). An extensive study involving adult educators concludes that the most important dimensions of quality are quality of instruction, quality of administrative recognition, quality of advisement, quality of technical support, quality of advance information, and quality of course evaluation (Harroff 2003). Another elaborate study of important quality factors in online education in Korea concluded that interaction, staff support, institutional quality assurance mechanisms, institutional credibility, student support, information and publicity, and learning tasks shape students' perception of online education quality (Jung, 2011).

Online courses and programs have attracted non-traditional students. This has contributed to enrollment growth of online education. This group usually brings their experience to the classroom and enhances richness of discussions. They are diverse in terms of academic preparedness and social and ethnic backgrounds and feel less prepared for the use of technology and querying information than traditional students. Although student involvement and engagement are important factors for student retention, these factors were even more important in their first year. About 50 percent of these students felt that support services provided by their university were barely adequate (Davis, 2016). In response some universities have created an office that serves only the non-traditional adult students to help them stay enrolled in their program.

These college and university offices focus on helping with transition of non-traditional students to academic environment. They help non-traditional students become more educated and better informed of non-traditional scholarship programs, the registration process, academic advising and counseling services, field and career options, student health services, student parking, the 
financial aid process, student housing, networking with peers/colleagues, commuting issues, and even have staff available to answer questions regarding courses, programs, and/or instructors (Hardin, 2008). Davis (2016) indicates that higher education institutions should assign knowledgeable, well-trained, and personable advisors who understand the needs of nontraditional adult students and can guide them to achieve their education goals. Providing guidance related to specific types of learning, study skills in online environments, time management, the balancing of educational and other life demands, collaboration methods, library organizations and searches, honor system, and social connections improves student retention and success (Koehler \& Burke, 1996).

\section{The bird's-eye view of an established online program delivery system}

Higher education institutions with established online programs delivery system have the equivalent of most of the units and offices that they have for support of their face-to-face program delivery system for support of their online course delivery system. These include the specific expertise in instructional design, curriculum development, presentation platform, testing system, information and communication technologies, knowledge experts, registrar, financial aid, advising, tutoring and learning aids, student services, and leadership for online program development and delivery system. For the sake of brevity, this paper does not present a detailed description of these items. Instead, the following section lists the major units of established online program delivery systems and the functions they perform when there is a need for quick conversion of face-to-face courses to online. Higher education institutions must perform these same functions as well as possible no matter how established their online course delivery structures are. 


\section{Quick conversion of face-to-face courses to online courses}

The authors' experience in developing online courses and observing the development of online courses suggest that an online course in their university that has established support structures for online course development and delivery takes between six months to two years depending on how complex and elaborate the online course would look and feel. Therefore, expectations of online course quality must be managed when the faculty and the support system do their best to convert face-to-face courses to online abruptly, while trying to preserve the level of quality that represents the reputation of the institution. This is especially important when the institution has been geared mostly to offering face-to-face programs and has not developed and established a specific level of quality for its online courses and programs.

\section{Basic technology requirements}

At the most basic level faculty and students must have access to computing technologies with appropriate power and accessories, and high-speed access to the Internet to participate in online courses. The most basic accessories are audio and video cards or equipment and hotspot drive for those who do not have steady Internet access. Video recording software such as Camtasia and PowerPoint should be available for faculty for recording of their instructional materials. Other accessories such as digital writing pads and digital document readers should be available to enhance communication quality and save communication time and effort.

Administrators should make sure that all faculty have the necessary tools and technologies for creating and offering online courses. The institution or college emergency plans usually include faculty contact information. This information can be used to contact all faculty to determine their technology needs. The required technologies should be made available to faculty as quickly as possible. The institution should create a pool of the basic technologies and devices 
for students' checkout to make sure that students have access to the technology they need to succeed.

\section{Online course development}

Proper course development has been identified as an important determinant of the quality of online courses (Frydenberg 2002; Mostafa 2006). Online course creation should be a collaborative effort between the faculty member, instructional designers, curriculum specialists, and technology specialists who are trained in the preferred ways of presenting courses online for student learning.

Depending on the existence of these types of professionals and their availability, a multi-pronged approach can be used to help the faculty in converting their face-to-face courses to online. One is to offer webinars and online workshops for faculty to introduce them with the educational technologies that are used in online courses. Second is to assign instructional designers, curriculum specialists, and technology experts to faculty to create online courses. Third, assign faculty with experience in online course development to mentor the faculty who do not have the necessary experience. Fourth, offer webinars and literature on what type of technologies to use and how to use those technologies to create effective online courses. Fifth, offer webinars on a variety of topics that present factors in online courses that result in better presentation of materials and student learning. Some examples of the webinars, workshops, and literature are on how to:

- deploy online pedagogical concepts in developing online courses

- create and embed video on the learning platform

and webinars on:

- pedagogical practices for developing online courses 
- Graduate online teaching debriefs---Specifics on graduate instruction.

All course materials including the course syllabus, e-book, course assignments, video lectures and instructions as well as other instructional materials should be available on the online platform and easily accessible to students. The online materials should also include information on how to access and use the online platform, the required specifications for students' computers, and information on how to access and use the testing system, advising, tutoring, library. Instructors should be very cognizant of the fact that because this is the main way for students to interact with the course, these materials must be extremely self-explanatory, user-friendly, easy to follow, and done in a very professional way. Course syllabi must highlight course expectations, information on assignments, due dates, exam dates, and supplemental materials. The materials should be personalized for students and their learning styles and consider the whole system and students (Masoumi \& LindstrÖm, 2012).

\section{Instructors}

Webinars, online workshops, and literature should be provided for instructors to give them information related to online pedagogical issues and in-depth knowledge of the learning platform that contains the course materials, other course components, and supplemental resources. They should also be taught techniques that enhance student participation and make students interested in learning and participating in class discussions and activities. Faculty who teach online courses should also be taught on how to use communication technologies and group meeting software that improve students' interaction with their classmates and the faculty. Some examples of the webinars, workshops, and literature are on how to:

- organize an online course on the learning platform

- use VoiceThread for assignments on the learning platform 
and webinars on:

- best practices and teaching tips for the online classroom

- $\quad$ key pedagogical strategies for online teaching

- When teaching online, Consider alternatives to timed testing

Students' perception of instructor's compassion - being friendly, patient, and respectful to students - significantly affects their experience in online courses. Online students usually try to resolve learning issues by themselves which may make them frustrated. Instructors should respond to students' enquiries quickly and with compassion to make students feel more welcome and comfortable. Instructors are encouraged to carry mobile technologies such as smart phones and tablets while out of office or home for a relatively long periods to use and respond quickly to students' questions. In addition, instructors should make online calendar and appointment systems available to online students to allow students arrange for online meetings. Faculty and students should be trained through webinars and brochures in the use of technologies that can be used in tutoring sessions. Examples of webinars related to these issues are:

- Crisis Pedagogy Starts with the Human Touch (With the nation buffeted by two major crises, it's more important than ever to check in with our students. And with our colleagues as well.)

- We have embraced technology; now let's humanize it

- Continually communicate with your students to establish clear expectations and avoid confusion and uncertainty.

- For office hours and advising, please let your students know that you will be available by phone, email, or through other technologies. 
- Issues related to adjusting to the physical pains of working at home, online resources, motivating and or engaging students online

\section{Learning platform}

Course delivery is a significant factor in online course quality (Frydenberg, 2002).

Usually, higher education institutions use one platform for delivering all online courses.

Institutions should specify a standard presentation format for course information and content.

Following the standard presentation format saves students' time by making it easy for them to become familiar with the presentation format quickly and improves their ability to interact and navigate the learning platform. This provides more time for students to spend on learning the materials while keeping students' frustration low as they do not get confused by having to work with different formats in different courses.

The following four design principles are provided by Southern Poly State University as a guide for developing online courses: consistent layout and design, clear organization and presentation of information, consistent and easy-to-use navigation, and aesthetically pleasing design and graphics (Butcher and Wilson-Strydom, 2013). Modular format presentation of course contents is highly desirable for students because they will be able to arrange and rearrange course content to the way they prefer to view the site and spend more time and learn better (Masoumi \& LindstrÖm, 2012). Students should also be able to provide feedback through the learning platform during and at the end of the semester. Feedback forms can be included in each course unit or module. Instructors may use the students' feedback to make necessary adjustments during and at the end of the semester. 


\section{Synchronous lectures}

Given the short time for switching face-to-face classes to online, some faculty may not have enough time to develop a high-quality online version of the course. Instead, they may give lectures online synchronously at the designated time for the face-to-face class. The required technology for these synchronous lectures may require video devices and digital writing pads.

\section{Office hours}

Faculty continues to hold office hours online at the specified days and times as indicated in the course syllabus. Students may also make appointments to meet the faculty online at other times. Online calendars may be available to students to simplify the appointment process. The required technology for these online meetings may range from regular phones to video devices, document readers, and digital writing pads.

\section{Learning aids}

Tutoring should be available for online courses. This can be challenging because it may require sophisticated communication technologies that enable both tutors and students to share digital documents and images of hard copy documents. The system should also include screen and whiteboard sharing technologies to allow for timely and effective tutoring. Online tutorial videos and documents should be available to students to improve tutoring effectiveness.

\section{Testing system}

Online students must take their tests online when the university is closed. Some of the options are take-home exams, Blackboard with lock down browser, or hiring proctoring companies to proctor exams using either live or automated proctoring. Subject matter experts offer appropriate alternatives for administering exams. These alternatives consider the field of instruction and the type of test. For example, performing arts courses that require performance 
may use a different type of test than a psychology course that requires knowledge of the course contents.

\section{Advising}

Advising online students requires high skills in using a variety of a variety of online technologies and communication software. These skills should be the subject of webinars and instructional materials designed for advisors. Advising directors and institution's administrators should identify the sources of these webinars and online workshops and arrange for their presentation to the advisors.

\section{Other student support services}

Online programs should have the online equivalent of all of the face-to-face student support services. Some of these offices are computing services, library, student services, educational accessibility, registrar, financial aid, health services, counseling, internship and placement, international students, and housing. Webinars and online workshops on the use of computing and communication technologies and the specifics to their roles of support services for students and faculty should be provided to the staff in these units.

Staff serving online students should also be provided webinars and specialized online training workshops on how to resolve the many logistical and technical needs of online students. This training should enable the staff to resolve the issues, and to guide students to the appropriate groups or units that can resolve students' issues.

Students may run into technical problems in different forms such as problems with the learning platform, online labs, communication technology, or students' computer. Technical help is a very important component of online programs (Osika, 2004). When students face technical difficulties, their progress stops or is severely interrupted until those problems are resolved. 
Technical issues are frustrating to online students, wastes their valuable time, and disrupts their effective learning. These difficulties negatively impact online students who rely heavily on technology for accessing course contents and communication with other students, faculty, and staff. Therefore, the university should provide timely solutions to these problems. On-time help should be available to resolve these problems on a timely basis.

Maintaining a safe learning environment for students is an important service factor (Mostafa, 2006). In online education, the focus is on protection of students' computers and data against cyber-attacks that can also be routed through university systems (Rhiel, et al. 2016). Computing offices should be cognizant of this fact when many more students go online for their education. Examples of the support for students and faculty are:

- Establish an emergency call center to provide emergency services such as counseling, health Services, and educational accessibility.

- Connect students with food resources

- Provide emergency housing for native and international students as well as emergency food supplies.

- Allocate funds to keep students employed through teleworking arrangements.

- Provide virtual information sessions, virtual campus tours, meetings with financial aid counselors, admission counselor check-ins with students and families for prospective students.

- Discuss the impact of COVID-19 on female faculty research productivity

- Engaging faculty and staff with disabilities.

- Discuss the impact of COVID-19 on faculty research habits

- Provide resources to help search committees conduct interviews and virtual campus visit 


\section{Conclusions}

This paper presented factors that are important in developing and delivering online courses and programs. It discussed the major units and functions involved in online delivery system. The discussions illustrated that establishing online education systems for offering online courses and programs require extensive investments in money and time over a long period of time to acquire and set up the required technologies, hire skilled professionals for a variety of support services, and train faculty, staff, and students to perform well in the online environment. In special circumstances such as the one presented by the COVID-19 universities may have to convert all their face-to-face courses to online. This is a very challenging task even for universities that have an established online program delivery system. This conversion is extremely challenging for universities that offer all or most of their courses face-to-face. This paper presented the major activities that a quick and effective conversion from face-to-face to online should consider. The recommendations are in part based on the authors' experience in developing several online courses and converting their face-to-face courses to online very quickly in the COVID-19 emergency. Higher education institutions are powerful sources of energy, intellect, and problem-solving ability. With strong and clam leadership they can acquire the basic technologies and train the faculty and staff quickly to convert their face-to-face courses to online while trying to achieve the quality that is in line with the quality level defined in their organization's strategy. 


\section{References}

Alsaaty, F. M., Carter, E., Abrahams, D., \& Alshameri, F. (2016). Traditional versus online learning in institutions of higher education: minority business students' perceptions. Business and Management Research, 5(2), 31-41.

Arasaratnam-Smith, L., \& Northcote, M. (2017). Community in online higher education: Challenges and opportunities. The Electronic Journal of e-Learning, 15(2), 188-198.

www.ejel.org

Arinto, P. (2016). Issues and challenges in open and distance e-learning: Perspective from the Philippines. International Review of Research in Open and Distributed Learning, 17(2), 162180.

Bawa, P. (2016). Retention in online courses: Exploring issues and solutions-A literature review. SAGE Open, January-March, 1-11. doi: 10.1177/2158244015621777

Benson, A. D. (2003). Dimensions of quality in online degree programs. The American Journal of Distance Education,. 17(3), 145-159. doi: 10.1207/S15389286AJDE1703_2

Butcher, N., \& Wilson-Strydom, M. (2013). A guide to quality in online learning. https://www.academicpartnerships.com/Resource/documents/A-Guide-to-Quality-in-OnlineLearning.pdf

Butcher, N., \& Wilson-Strydom, M. (2013). A guide to quality in online learning. https://www.chea.org/userfiles/uploads/A Guide to Quality in Online Learning.pdf

Chua, A., \& Lan, W. (2007). Quality assurance in online education: the universitas 21 global approach. British Journal of Educational Technology, 38(1), 133-152. doi:10.1111/j.1467-8535.2006.00652.x

Davis, S. D. (2016). A Comparison of face-to-face on-campus and distance education undergraduate nontraditional adult students' academic, social, and environmental needs in the collegiate setting, Dissertation, Auburn University.

Frydenberg, J. (2002). Quality standards in e-learning: a matrix of analysis. International Review of Research in Open and Distance Learning, 3(2), 1-15.

Ganesh, G., Paswan, A., \& Sun, Q. (2015). Are face-to-face classes more effective than online classes? An empirical examination. Marketing Education Review, 25(2), 67-81.

Gray, J. A., \& DiLoreto. M. (2016). The effects of student engagement, student satisfaction, and perceived learning in online learning environments. International Journal of Educational Leadership Preparation, 11(1).

Hanan, J. A., Mundy, M.A., \& Kupczynski, L. (2015). The effects of age and gender on student achievement in face-to-face and online college algebra classes. Research in Higher Education Journal, 27, 1-22. 
Hardin, C. (2008). Adult students in higher education: a portrait of transitions. New Directions of Higher Education, 144(1), 49-57.

Harroff, P. A. (2002). Dimensions of quality for web-based adult education. Dissertation, The University of Georgia, Athens, Georgia.

Jaiyeoba, O. O., \& Iloanya, J. (2019). E-learning in tertiary institutions in Botswana: Apathy to adoption. International Journal of Information and Learning Technology, 36(2), 157-168.

Jung, I. (2011). The dimensions of e-learning quality: From the student's perspective. Education Technology Research Development, 59(4), 445-464.

DOI 10.1007/s1 1423-010-9171-4

Koehler, G., \& Burke, A. (1996). Transforming the treadmill into a staircase: Preparing nontraditional first-generation college attenders for success. Unpublished manuscript. Retrieved from ERIC database. (ED414959).

Lee, J. W. (2010). Online support service quality, online learning acceptance, and student satisfaction. Internet and Higher Education, 13, 277-283.

Mariasingam, M. A., \& Hanna, D. E. (2006). Benchmarking quality in online degree programs status and prospects. Online Journal of Distance Learning Administration, 9(3).

Markova, T., Glazkova, I., \& Zaborova. E. (2017). Quality issues of online distance learning. Procedia - Social and Behavioral Sciences 237, 685 - 691.

McGorry, S. Y. (2003). Measuring quality in online programs. Internet and Higher Education. 6, $159-177$.

Masoumi, D., \& Lindström, B. (2012). Quality in e-learning: a framework for promoting and assuring quality in virtual institutions. Journal of Computer Assisted Learning. 28(1), 27-41. doi: $10.1111 / \mathrm{j} .1365-2729.2011 .00440 . x$

Mostafa, M. M. (2006). A comparison of SERVQUAL and IP analysis: Measuring and improving service quality in Egyptian private universities. Journal of Marketing for Higher Education, 16(2), 83-104.

Osika, E. R. (2004). The concentric support model: A model for the planning and evaluation of distance learning programs. Dissertation, Purdue University.

Phipps, R., \& Merisotis J. (2000). Quality on the line: Benchmarks for success in Internet-based distance education, Washington, DC: Institute for Higher Education Policy.

Quiroz, R. E., Ritter, N. L. Li, Y. Newton, R. C., \& Palkar, T. (2016). Standard based design: Teaching K-12 educators to build quality online courses. Journal of Online Learning Research, 2(2), 123-144. 
Rhiel, G. S., Ardalan, A., \& Wermus, M. (2016). Theoretical classification of factors that affect quality of service in colleges and universities' online programs. International Journal of Education Research, 11(1), $54-69$.

Sozudogru, O., Altinay, M., Dagli, G., Altinay, Z., \& Altinay, F. (2019). Examination of connectivist theory in English language learning: The role of online social networking. International Journal of Information and Learning Technology, 36(4), 354-363.

Tichavsky, L. P., Hunt, A. N., Driscoll, A., \& Jicha, K. (2014). It's just nice having a real teacher: Student perceptions of online versus face-to-face instruction. International Journal for the Scholarship of Teaching and Learning, 9(2), Article 2.

Tyler, R. W. (1950). Basic principles of curriculum and instruction: Syllabus for education 305. Chicago: The University of Chicago Press.

Young, A., \& Norgard, C. (2006). Assessing the quality of online courses from the students' perspective. Internet and Higher Education, 9, 107-115.

Wingo, N. P., Ivankova, N. V. and Moss, J. A. (2017). Faculty perceptions about teaching online: Exploring the literature using the technology acceptance model as an organizing framework. Online Learning, 21, (1), 15-35.

Zhao, F. (2003). Enhancing the quality of online higher education through measurement. Quality Assurance in Education, 11(4), 214-221. https://doi.org/10.1108/09684880310501395 